\title{
A Neo-Rawlsian Approach to Residential Integration
}

\author{
Kevin J. Brown
}

Department of Business, Economics, and Political Science, Asbury University, 1 Macklem Drive, Wilmore, KY 40390, USA; E-Mail: kevin.brown@asbury.edu; Tel.: +1 8598583511; Fax: +1 8598583921

Submitted: 15 July 2013 | In revised form: 22 August 2013 | Accepted: 23 August 2013 |

Published: 29 August 2013

\begin{abstract}
Over the past 40 years, the United States has engaged in various policies to integrate otherwise segregated black and white households within a shared space. However, little work has been done to fully articulate a moral argument for residential integration among black and white households. This paper offers what I refer to as the normative argument, which possesses two morally-impelled arguments for residential integration. Since the ethical appeal to integrate is often couched in the language of justice, I begin with a frameworkbased upon the work of the late philosopher John Rawls-for considering the moral aspects of residential integration. However, I go on to point out intractable problems related to the Rawlsian framework that would fail to flesh out all ethical considerations of the normative argument. From here, I provide a revised, or neo-Rawlsian, framework for understanding residential integration which addresses the aforementioned problems. This exercise is both important and necessary for the future of residential mixing, as better understanding the moral and ethical attributes of this discussion is, perhaps, the best means to lubricate the fundamental shift from 'spatial' to 'social' integration.
\end{abstract}

Keywords: common good; integration; John Rawls; liberalism; residential housing; segregation; social capital; social integration

\section{Introduction}

Today in the United States, the chasm of black-white race-relations remains evident throughout various sectors and institutions in society. One area where this is most clear is in housing arrangements: white and black households are not typically integrated within the same space. However, within the US, we can find several policies directed toward racial and socioeconomic de-concentration over the last 40 years as a means to mix communities with the intended outcome of increasing or enhancing life chances of low-income minorities.

For example, the Chicago Gautreaux Initiative or the multi-state Moving to Opportunity Program were efforts to literally move low-income minorities into more racially and economically heterogeneous neighborhoods (what has been referred to as a "TenantBased Approach") ([1], p. 4). The Gautreaux Program originated from a series of class action lawsuits that were filed against the Chicago Housing Authority (CHA) in the US and the Department of Housing and 
Urban Development (HUD) where it was alleged that the housing authorities deliberately segregated lowincome African-Americans through tenant and site selection. As a result of the lawsuit, a new program named after plaintiff Dorothy Gautreaux was created in 1976 that offered vouchers and rent subsidies allowing for eligible families to move to desegregated areas throughout the region. By the year 2000, the Gautreaux Program had placed thousands of families into new homes (often times within newer, lesspoverty stricken areas). Planners were inspired by preliminary results from the Gautreaux program, and this evidence informed expectations for Moving to Opportunity. Thus, the Moving to Opportunity (MTO) program was created in the early 1990s as a longitudinal effort that used the poverty rate of the receiving neighborhood rather than its racial composition as the dispersal criterion. Families living in poverty-stricken areas were eligible to receive counseling and apply for assistance to move to a low-poverty neighborhood. The results of these initiatives continue to be explored and researched to the present.

Other programs, such as HOPE VI funding or Fair Share Housing legislation, seek to renovate lowincome public housing to create residential mixedincome and mixed-race housing environments (what has been referred to as a "Unit Based Approach") ([1], p. 4). The HOPE VI program was launched in 1992 and facilitated by the US Department of Housing and Urban Development. HOPE VI grants continue to be awarded for community revitalization initiatives. Fair Share Housing legislation-such as the Mount Laurel, New Jersey rulings-require that every town provide a "fair share" of low- to moderate-income (LMI) housing. This ruling engendered public-private cooperation in addition to cooperation between the suburbs and the cities to rehabilitate urban housing as a way of meeting their fair share requirement.

These aforementioned initiatives differ in their focus on how they address segregation (de-segregation; integration) as well as their target group (race; class). Describing the underlying motivation for integration policy, Sociologist John Logan writes: 'neighborhood integration has remained a goal of public policy and popular opinion because it is seen as proof of the American ideal of equal opportunity' ([2], p. 1).

One of the major issues related to segregation data is not simply where households are segregated from, but where they are segregated to. Indeed, patterns of residential segregation are often associated with stark inequalities related to housing, education, health, labor opportunities, safety, and local resources and amenities. These fundamental features for stability in an advanced democracy are disproportionately secured by white households relative to black households in a racially segregated nation. Thus, it has been concluded that 'Segregation [...] is the key factor responsible for the creation and perpetuation of communities characterized by persistent and spatially concentrated poverty' ([3], p. 118). In addition to segregation demonstrating a deleterious effect on housing values for black segregated areas, it has been positively associated with increased unemployment, poorer educational results, and neighborhood crime ([4], see also $[5,6])$. Further, segregation has been correlated with lower socio-economic status and racial disparities in health [7]. Given this evidence, it is little wonder that social and economic outcomes for blacks are substantially worse, both in absolute terms and relative to whites, in racially segregated cities [8]. Authors Dreier and Moberg (2001) summarize the problems of segregation and what appears to be the intuitive solution: integration.

As politicians and policy analysts revisited the thorny problems of urban poverty in recent years, they seemed to be arriving at a rare consensus: poor people are hurt by their concentration in large, inner-city neighborhoods that further social isolation and racial segregation. In this view, it would be better to disperse poor people and minorities, putting them in closer proximity to jobs, decent suburban schools, and safe communities [9].

This, in essence, is at the heart of the integration idea. It is the belief that segregation is the cause of myriad social ills and integration is a key remedy to this problem.

Despite this evidence and its apparent relation to residential segregation, it is unclear that 'integration' is, indeed, the appropriate solution. Schwartz and Tajbakhsh (1997) advise that while housing policy that encourages racial mixing is a recent trend, the effectiveness of such policy remains questionable until a more robust understanding of social benefits, costs, and preconditions can be sufficiently answered. Until then, they write, advocacy of mixed-housing will be based 'largely on faith' ([10], p. 81).

Despite this skepticism, most who advocate for integration initiatives share a common assumption: the underlying belief that 'segregation is harmful.' Indeed, it has been said that 'few would dispute that racial segregation and concentrated poverty are ongoing challenges' ([11], p. 7). Thus, the assertion that segregation is not good for society holds nearly universal agreement among social scientists and a comprehensive review of the literature would only serve to verify this claim. Yet the core of the issue has less to do with whether segregation is not good and more to do with whether mixing is good. If segregation is the problem, is mixing the solution? Based upon the empirical evidence to date, there is little evidence to definitively support an affirmative answer to this question. In their 2010 book 'The Integration Debate'-Hartman and Squires describe the segregation/integration quagmire well: 'this book provides a harsh reminder of the grave costs of segregation. But it also identifies some of the perhaps unintended consequences that have been encountered in at least 
preliminary efforts to realize more integrated living patterns' ([11], p. 7).

With this in mind, we might remark that there will, perhaps, never be a unified voice as it relates to residential integration and mixing. However, this article aims to offer a new vantage point. The residential integration discussion has been presented and understood under a guise of economic efficacy and the maximization of utility in an aggregate social context. In other words, the goals of mixing programs have sought to improve the welfare and well-being of lowincome minority households in such a manner that the benefits exceed the costs of such programs. The intended outcomes related to integration programs are consistent with this framework, as they seek to de-concentrate citizens for reasons of security, better homes and schools, job opportunities, and a more equal expression of citizenship. If we were only to view these outcomes in a vacuum, we might rightly understand residential segregation as solely an economic problem-particularly as it relates to matters of distribution and, as Elizabeth Anderson describes it, participation in society [12].

However, discussions of residential integration on strictly economic terms without deference to other moral and ethical considerations can be problematic in itself. More specifically, if we understand integration strictly through the lens of the existing framework, are important ethical questions left to the side? This is not to suggest that the utility framework for integration is not a moral framework in itself. Indeed, such a framework has an explicit moral dimension-one that is referenced throughout related literature (particularly where intended integration outcomes are expressed in terms of justice). Improving the lives of segregated minorities through integration initiatives aligns with an array of democratic ideals that are replete with values such as rights, equality, fairness, and equal opportunity (values that are often expressed in economic terms but are ethically driven). In a technical sense, then, the issue has less to do with the presence of ethical reasoning, but rather, is more concerned with the nature of the ethical reasoning that may be absent by virtue of using a utility-based paradigm to evaluate integration.

By including a more capacious ethical paradigm in this discussion, we have grounds to state that 'mix'not necessarily 'mixing'-is good. This is important because mixing strategies have occurred as a result of segregation. They have not occurred, however, from the premise that mix is good. Engineered mixing as a blunt welfare instrument may indeed be a poor device for securing and protecting the welfare and well-being of low-income segregated members of society. However, to communicate the appeal for integration strictly in these terms is to miss and even exclude important normative features.

The balance of this paper is arranged as follows: in Section 2, I begin by stating two normative attributes that are primary in the residential integration discussion. Simply stated, these attributes comprise what I shall refer to as the normative argument. In Section 3, I attempt to provide a philosophical justification for this argument. Specifically, I draw upon the work of John Rawls as a means to support residential integration in a more explicitly moral and ethical manner. However, while Rawls may provide strong ethical support for the first tenet of the normative argument, his framework is a poor foundation for the second. Thus, in Section 4, I offer a neo-Rawlsian model that I submit to be a more appropriate framework for understanding and deliberating upon the moral and ethical features of residential integration. I summarize the implications of this model in my conclusions.

\section{The Normative Argument}

Evaluations of residential mixing have relied upon a general utilitarian ideology. Here, I utilize the term 'utilitarian' in its most general sense: the maximization of utility (the greatest 'good') in an aggregate social context (the greatest 'number'). Thus, to determine efficiency, the optimal arrangement is the one that provides maximum aggregate utility.

I submit, however, that the multifaceted nature of integration, community, and US race relations are not adequately captured in a utilitarian framework, given the singular aim of such a framework. This statement begs the question: what facet(s) of residential integration is the utility framework failing to capture? Here I offer two primary ethical elements relevant to residential integration that have escaped the utility framework as I have defined it. I shall hereafter refer to these elements as the normative argument for residential integration.

The first is the issue of societal fairness and social equity based upon the presence of enhanced risk and vulnerability occurring as a function of living in a racially segregated community. Simply put, we might state that it is unfair when sectors of society are more socially or economically vulnerable and 'bear a disproportionate share of environmental risks' ([13], p. 131). While the efficiency model may be of great importance insofar as providing the optimal social arrangement for utility maximization, it often fails to consider the distribution of this utility. Sen (1997) writes: 'the trouble with this approach is that maximizing the sum of individual utilities is supremely unconcerned with the interpersonal distribution of that sum. This should make it a particularly unsuitable approach to use for measuring or judging inequality' ([14], p. 16). To summarize, we can describe the first ethical issue of the normative argument as relating to considerations in social equity.

The second ethical element that the existing utility framework fails to address is the trajectory of integration's end. Velasquez (1982) suggests that the major drawback to a utility framework is its inability to 
deal with moral issues ([15], pp. 53-54). This is not to suggest that such a framework is amoral or devoid of ethical considerations. However, they are ethical considerations of a very specific kind. For example, most integration initiatives are born out of a desire for enhanced welfare and equal opportunity. While this is appropriately understood as a moral consideration, the rightness of this ethic is based upon the consequence of the activity in question, expressed in material terms (i.e., morally appropriate if integration equals more welfare). This consequentialist approach, commensurate with traditional economic cost-benefit discourse, seems to limit the full range of ethical considerations as it is still conceived under the greater paradigm of utilitarianism. Dismissing consequentialism is problematic, however, as an alternative motivation would also aim toward a specific end. Thus, it is important to distinguish between integration as a means to promote material ends and integration as a means to promote moral and ethical ends beyond economic welfare. To pursue the latter is to ask: 'is it right?' in contrast to 'Does it work?' [16] We might say that this argument addresses how we value integration. In other words, should we have an equitable arrangement, albeit a segregated one-is this an arrangement worth aspiring toward? Is this the most morally appropriate arrangement? To summarize, we can describe the second ethical issue of the normative argument as a pluralistic valuation of integration.

Specifically, one of the important features of the normative argument's second tenet involves the recognition that existing in the same space and integrating within that space are not the same. Karst (1985) makes the important distinction between physical exclusion and social exclusion, i.e., exclusion from 'belonging' ([17], p. 323). While one may be physically included in spatial terms, that does not necessarily mean they belong. We might refer to this distinction as the difference between spatial integration and social integration. While the latter requires the former, the former does not necessarily lead to the latter. Later in the paper, more attention will be given to this distinction.

On the whole, such moral reflection has been notably absent in the existing appraisal of mixedcommunity initiatives [18]. As discussed, some scholars have critiqued residential integration as constituting nothing more than a 'faith-based displacement activity' [19]. In response, we might ask: is there space for a normative element in our evaluative framework as it relates to residential social arrangements? Can residential integration endeavors be substantiated on ethical values or principle beyond what we may hear in common economic and material considerations? While the absence of this line of inquiry in the existing literature might leave us skeptical as to the relevance of ethics in the residential integration debate, valueladen ideals and language can often be found in social mix discussions. These ideals are best captured in the language of justice.

\section{Supporting the Normative Argument- Rawlsian Justice and Social Integration in Housing}

If our aim is to incorporate an ethical component in the integration discussion as identified in the normative argument, such an argument would likely find support and justification in the field of justice. To be sure, utilitarianism proper is not antithetical to justice, and further, is considered a form of justice. However, as mentioned, this particular brand of justice, as I have defined it, risks bracketing out the ethical components identified as being necessary in our understanding of housing arrangements. Therefore, to give full support to the normative argument and flesh out its contributions relative to the integration discussion, it is appropriate to begin with a conception of justice articulated against the backdrop of utilitarian ideology. The seminal expression of such justice is found in the work of John Rawls. Jon Mandle (2009) writes: 'although the term "justice" is used in a [sic] many different contexts, justice as fairness addresses a fairly narrow topic, although an indisputably important one. It is concerned with what we might call "basic social justice"' ([20], p. 11). Rawls' work is known for an array of important characteristics, but it is best understood as a response to utilitarian conceptions of justice, or what he calls the 'predominant systematic theory' in modern moral philosophy ([21], p. vii). He describes the brand of utilitarianism he is responding to: 'the main idea is that society is rightly ordered, and therefore just, when its major institutions are arranged so as to achieve the greatest net balance of satisfaction summed over all the individuals belonging to it' ([21], p. 22).

Rawls' theory of justice offers a promising ethical framework for exploring the inequality of impacts relative to segregated black and white households. His approach is favored as possessing a greater degree of 'egalitarian criteria' for a system of justice and helps to concentrate the 'variety of principles of equity, fairness and justice held and applied independently' by 'ordering and prioritizing or tradeoff' ([14], p. 501). Further, his theory of justice provides an alternative to otherwise consequentialist systems of determining what should or should not be done-a necessary step in the survey of fairness and justice in housing arrangements. It has been said that Rawlsian justice is employed where institutions 'undertake to avail themselves of the accidents of nature and social circumstances only when doing so is for the common benefit' ([22], p. 2021).

Rawls' theory of justice is based on the principle of social contract, or the idea of giving up certain rights and liberties so as to enhance social order. However, this social contract is not necessarily an historical reality, but rather, it is an imaginary device used to discover our moral principles [23]. The purpose of the contract is to elucidate what is just, and moreover, to arrange society around just ideals. 
How does one go about determining what is just? Rawls proposes that justice be constructed in a neutral state where the following question is considered: what principles would we live by if we knew we would have to live together in a society governed by these principles but did not necessarily know our place in society? Rawls proposes a hypothetical state where individuals are unaware of their natural abilities, place, and position in the social hierarchy of society. This hypothetical state is referred to as the 'original position'. He writes:

By contrast with social theory, the aim is to characterize this situation so that the principles that would be chosen, whatever they turn out to be, are acceptable from a moral point of view. The original position is defined in such a way that it is a status quo in which any agreements reached are fair. It is a state of affairs in which the parties are equally represented as moral persons and the outcome is not conditioned by arbitrary contingencies or the relative balance of social forces ([21], p. 120).

It is in this equilibrium, according to Rawls, that societal decisions should be made. Decision making without assuming one's particular standing in society, class position, or social status is referred to as the 'veil of ignorance' [21]. The outcomes of decision-making in this equilibrium should be an acceptable standard to all parties for a just distribution of social goods such as liberty, income, wealth, and opportunity [24]. In other words, if one had no influence relative to where they were born, what abilities they were born with, and what future fortunes they would have, they must articulate what kind of society they would choose to frame so as to ensure their standing in society and opportunities for advancement were equal, fair, and just, and not simply subject to the 'luck of the draw' in a social lottery [25].

While there is much to be said about Rawls' theory, we can conclude that Rawlsian justice would give support to the notion of integrated communities or social institutions that support integrated settings for low-income minority-segregated households who find themselves more vulnerable and at-risk in society as a function of their segregation. In other words, the Rawlsian exercise would support the first tenet of the normative argument by suggesting that we would not choose a housing arrangement marked by segregation and inequality. The fact that I may be born into a society where I do not know my skin color and yet must decide how I would arrange housing, leaves me open to living in a residentially segregated white or black neighborhood. If I were to live in the latter, I would be compromising my desire to maximize primary social goods, or the attributes that all people behind the veil of ignorance desire in the society they will inevitably inhabit. These include liberties and opportunities, income and wealth, and the social bases of self-respect.
It should be pointed out that such a thought process is based upon the belief that minority-segregated neighborhoods potentially leave members more vulnerable and at risk to market or environmental forces. To be clear, not all segregation is harmful, and some have even argued that segregated enclaves-or 'specialized neighborhoods'-are optimal in many ways ([19], p. 5; see also [26]). However, these considerations must be weighed with the abundance of evidence supporting the notion that residential segregation is socially and economically sub-optimal for low-income minorities [27].

In light of the realities of segregated living patterns, we might rightly call residential segregation unjust. Because an unequal distribution of primary goods is not to everyone's advantage in this particular arrangement, Rawls would suggest institutions should be designed in order to satisfy the principles of justice forged behind the veil of ignorance [28]. This, in turn, would result in redressing the bias in social contingencies as overtures toward equality. Therefore, we might properly understand efforts such as the Gautreaux dispersal program, Moving to Opportunity, HOPE VI funding, and legislation such as the Mount Laurel rulings against exclusionary zoning-all efforts to engineer integration through housing - as appropriate overtures necessary for the achievement of Rawlsian equality.

At best, the Rawlsian exercise provides strong ethical rationale and support for the first consideration of the normative argument which recognizes the adverse effects disproportionately shouldered by segregated black households as a violation of social equity and fairness. When made ignorant of their natural and social contingencies, rational and mutually disinterested persons in the original position would not choose to structure society in such a way so as to leave some members more at risk and vulnerable. However, as we turn our attention to the second consideration in the normative argument, the same degree of support is altogether absent.

\section{Why Rawlsian Justice Will Not Do Justice to the Integrated Housing Discussion}

Rawlsian justice, a justice understood as distinct from utilitarian sentiments, while seemingly providing a credible theory of justice to buttress the first consideration in the normative argument, on closer inspection reveals insurmountable problems - two of which I shall emphasize - that stand as an impediment to the full expression of the second consideration. While there is a wide body of criticism against Rawls' two theories of justice, this particular critique has less to do with his theory in general and more to do with the usage of Rawlsian theory as a framework for justice in the residential integration discussion. That is to say, Rawls' theory-as it stands-is insufficient to support both tenets of the normative argument.

First, a Rawlsian framework can condemn the pres- 
ence of risk and vulnerability experienced by segregated black households, but it cannot necessarily place an intrinsic value on social integration. In other words, Rawlsian justice can condemn the consequences of segregation as morally wrong but cannot praise integration, in itself, as morally right.

The second problem of Rawlsian justice concerns the origin of his framework as being drawn from the liberal appeal to individual rights. A society seeking moral guidance for distributive principles based upon the language of rights has already presupposed a certain conflict among members of that society. A 'right' for one citizen is often understood as a right against another (e.g. property rights: 'my propertynot yours'). In other words, our rights-important as they may seem-reinforce the belief that others exist as a threat to my rights, and not the fulfillment of them. Further, this conflict is sustained, and perhaps exacerbated, in the appeal to one's rights. This argument finds a strong expression in Marx, who referred to a 'rights-based society' as a 'conflict society' ([29], p. 44). Thus, Rawlsian dependence on one's rights would ideally provide each person the opportunity to secure basic liberties, but at the expense of enhancing a greater sense of community.

In the context of residential integration, this would denigrate one of the more fundamental ethical aspects of the integration endeavor: social integration among community members (in contrast to mere spatial integration). While the scope of this article does not allow for more detailed attention to these aforementioned problems, we can say that both intractable problems reveal that Rawlsian justice undermines the cultivation of community and the moral power of solidarity that is inherent in the normative argument and which is also necessary to achieve the aim of socially integrating mixed neighborhoods.

\subsection{Thickening the Thin: A Neo-Rawlsian Approach}

If one accepts these arguments and agrees that Rawlsian justice is devoid of a certain sense of community and solidarity-both relationally-based concepts -then it is worth exploring what the inclusion of relationship would look like for Rawls and the subsequent implications for the support of the normative argument in residential integration. I submit that such an inclusion does not require a major overhaul to Rawlsian theory, but rather, can be envisaged in a minor adjustment of an earlier Rawlsian assumption. To explore this, we revisit Rawls' depiction of rational man found in the hypothetical original position.

The independence and self-regard ('mutually disinterested persons' behind the veil of ignorance giving consideration to their welfare) that Rawls assumes of actors in the original position is the lynchpin of the aforementioned problems arising from the Rawlsian framework. More specifically, notions of relationship and communal cultivation are notably absent in this picture of the rational Rawlsian agent. For Rawls, the autonomous features of 'independence' and 'selfregard' are necessary for individuals to achieve their own ends. There are two primary arguments against such a conception. While this article does not aim to give full attention to both, I am not the first to address them as problems within the Rawlsian model (for example see [30]). First, we could dispute the idea of an 'unencumbered self' that Rawls assumes. Second, we may dispute whether the existing Primary Social Goods (liberty, opportunity, money and wealth) -endowed to agents behind the veil of ignoranceare adequate to advance communal conceptions of the good, or the 'common good'.

Agents in the original position are ignorant of their eventual station in life, in addition to a host of other attributes, desires, characteristics, etc.- that they may have. They are aware, however, that they desire primary social goods. Rawls refers to this desire as a 'thin conception of the good'. In other words, while members are not considered thickly constituted selves -they do at least possess these basic desires. It is at this point that we can make a small adjustment to the Rawlsian exercise by 'thickening' his otherwise thin conception of the person in the original position. The move from thin to thick is a move from the person understood as an individual with preferences to be satisfied to a person 'whose identity and fulfillment are inextricably bound up with relations and communities' ([31], p. 143; see [32]). If we accept the terms of this adjustment, this will have significant implications for the support of the normative argument and our ethical interpretation of social integration in housing.

Thus, the adjustment I make to Rawls is a simple one: the person in the Rawlsian position, in addition to the other primary goods they desire, would also desire meaningful relationships. I define 'meaningful relationships' as follows: the intrinsic desire for participation and membership in social networks consisting of the norms of reciprocity and trust whose object is the good of another. I understand this addition to be a general purpose means useful for tempering the existing primary goods in addition to carrying out the variety of ends people may choose (whether they be of a individualistic or communal nature). Although this is a small and simple change, it has significant implications. This article does not aim to deliberate as to each and every change the addition of this primary good may potentially create. Rather, my aim is to focus on the implications that have particular relevance for the normative argument in housing and the ethical paradigm of residential integration.

\subsection{Implications of the Rawlsian Adjustment}

In addition to the range of questions that assist to determine the final principles of justice for Rawls, a rational person, in the thickly-constituted sense, be- 
hind a veil of ignorance would desire three additional qualities of the societies they would inhabit:

a. Real, meaningful relationships with others;

b. Cultivation of identity through community and interaction;

c. Maximization of security; minimization of enmity.

Before elaborating on these additional qualities, it is important to note a distinction often made by social theorists upon examining social networks. When reflecting on human interaction and relationships, we might say the distinction relates to answering the question: 'relationship with whom?' Putnam (2000) writes: 'some forms of social capital are, by choice or necessity, inward looking and tend to reinforce exclusive identities and homogeneous groups' ([33], p. 22). This is referred to as 'bonding' capital in social capital parlance. Segregated neighborhoods, school fraternities, ethnic social clubs-or anything that demonstrates the 'reinforcement of homogeneity'-are all examples of bonding capital ([34], p. 10). Bonding social capital links groups that have much in common, and are often characterized by reciprocity and solidarity. This is different from bridging capital, characterized as being 'outward looking and encompass[ing] people across diverse social cleavages' ([33], p. 22). Racially integrated communities, ecumenical religious organizations, or diverse work environments are examples of bridging capital. Putnam notes that bridging capital is good for getting linked to external assets and information diffusion. Bridging networks also play a valuable role as it relates to cultivating self-identity and reciprocity among a wider range of diverse networks. Most social scientists whose work addresses social capital point to the importance of both bonding and bridging networks for a healthy society. It is important to point out, however, that the composition of bonding and bridging capital for social agents need not be equally pursued. For example, for low-income members of society, bonding networks will play a particularly important role (job networks, support systems, mobilized labor initiatives, etc.). While bridging capital is important and in many cases, necessary, the degree of bonding and bridging capital an agent possesses will vary in their social capital calculus. With this in mind, we may now explore the additional qualities a thickly-constituted self in the original position would desire.

First, they would desire real, meaningful relationships with other individuals. This desire is a direct reflection of the newly endowed attribute of meaningful relationships, and makes a baseline assumption that individuals are not simply sensory beings whose aim is to author and fulfill various desires. Rather, individuals are also relational and desire human engagement, social capital, affiliation, membership, and solidarity. These goods can be achieved through various social and political institutions such as family, clubs and sports, work and educational environments, shared public resources, and neighborhoods.
The desire for a real relationship has implications for both bonding and bridging capital. As Walzer (1983) writes: 'the primary good that we distribute to one another is membership in some human community' ([35], p. 31). He goes on to assert that men and women without membership are 'stateless persons' ([35], p. 31). Individuals possess the desire to engage in meaningful associations and to cultivate a sense of belonging through group identity. While meaningful associations can occur in a bonding or bridging framework, it is bonding capital that is most natural: 'bridging ties are harder to build than bonding ones' ([36], p. 280). Moreover, homogeneity often serves as the social lubricant for belonging and affiliation among individuals [33]. Putnam writes: 'for most of us, our deepest sense of belonging is to our most intimate social networks, especially family and friends'-i.e., our bonding networks ([33], p. 274). While real relationships may occur more naturally among similar individuals (i.e., homophily-'love of the same'), we should not dismiss the importance of bridging capital in achieving real relationships. Briggs (2007) writes: 'popular discussions of race in America often center on interpersonal relations [between white and black] -which relate so closely to the respect, security, and feelings of mutuality we all crave' ([37], p. 264).

Second, thickly-constituted persons in the original position would (a) understand that their identity is formed and shaped through community and relationships (not self-derived) and (b) as a result, actors in the original position would not desire strictly homogeneous relationships which would minimize the full scope of identity cultivation available to them. To the latter point, if community and interaction are identityshaping mechanisms, thickly-constituted persons in the original position would not desire a society that was segregated and strictly homogeneous, although they may equally place a limit on the degree of heterogeneity they encounter as well.

We might say that bridging capital would be attractive, particularly in a hypothetical state of ignorance, so as to ensure one's self-understanding and identity were not limited to one particular group. While bonding capital is a natural, and necessary, component of any society aspiring to community cohesion and social solidarity-there are disadvantages when bonding occurs bereft of bridging. Indeed, one may appropriately claim that ours is a society where bonding capital is disproportionately higher than bridging capital as it relates to black and white relationships. Emerson et al. (2001) write:

In the post-Civil Rights United States, the racialized society is one in which intermarriage rates are low, residential separation and socioeconomic inequality are the norm, our definitions of personal identity and our choices of intimate associations reveal racial distinctiveness, and where 'we are never unaware of the race of a person with whom we interact.' ([38], p. 7). 
Emerson's quote describes our present arrangement where the threat of limited identity looms amidst an otherwise diverse society. In a racialized society, should one be born white or should one be born black, the risk is to be limited to the norms, traditions, and identities that accompany that race. This has implications for path dependency and preference formation and therefore limits the full scope of human potential and self-understanding. It is here suggested that such an arrangement would be avoided by a thickly-constituted self in the original position.

Limited identity, however, is not the only risk in a society where bonding and bridging capital are disproportionate. Thus, thirdly, thickly-constituted actors in the original position would desire more security and less enmity. They would desire social arrangements that allow for human interaction and the advancement of given ends to flourish, unrestrained by the potential threat of forces that might jeopardize such goods. Not only would they desire the maximization of security, they would equally desire the minimization of enmity, meaning that they would want to minimize structures that incite or exacerbate hostility between parties.

Rawls notes that 'although a society is a cooperative venture for mutual advantage, it is typically marked by conflict as well as an identity of interests' ([21], p. 126). Rawls' liberal conception of the self and the existing primary goods he aims to secure and utilize to achieve his ends is not only consistent with, but may very well contribute to, a society 'marked by conflict'. It is such conflict, though, that thickly-constituted persons in the original position would want to avoid insofar as it is possible. Again, this has implications for the importance of bridging capital.

We might think of the argument as followsconsider Putnam's proposition:

Here is one way of framing the central issue facing America as we become ever more diverse ethnically. If we had a golden magic wand that would miraculously create more bridging social capital, we would surely want to use it. But suppose we had only an aluminum magic wand that could create more social capital, but only of a bonding sort. This secondbest magic wand would bring more blacks and more whites to church, but not to the same church, more Hispanics and Anglos to the soccer field, but not the same soccer field. Should we use it? ([33], p. 362).

The issue, writes Putnam, is that if we ignore this question, then 'our efforts to reinvigorate community in America may simply lead to a more divided society' ([33], p. 362). There are two relevant remarks to be made about a 'divided society'. First, it has less capacity to foster a healthy democracy in contrast to a more integrated populace. Gutmann (1998) observes that economically, ethnically, and religiously heterogeneous associations possess a greater capacity 'to cultivate the kind of public discourse and deliberation that is conducive to democratic citizenship' ([39], $\mathrm{p}$. 358). Similarly, Anderson (2010) points out, 'The ideal of democracy essentially involves relations of social equality' ([12], p. 102).

Second, a 'divided society' has greater capacity to foster antagonism between homogeneous groups. A strong presence of bonding capital bereft of bridging capital (closing gaps in social distance based on race, class, culture, etc.)-while creating strong in-group loyalty and membership-may equally produce strong out-group antagonism-i.e., animosity toward the 'other' [33]. Putnam warns of the potential for conflict among homogeneous groups when bonding, and not bridging, capital is the societal norm: 'a society that has only bonding social capital risks looking like Bosnia or Belfast' ([33], p. 279).

We may conclude, therefore, that a society bereft of the presence of bridging capital may serve to ensure that one is born into a society with enmity; born into conflict. We may equally say that such a society would not be 'secure.' For the reasons above Briggs concludes that 'social bridges resting on intergroup ties have important consequences for individuals and for society, for social equality as well as for democracy' ([37], p. 265).

\subsection{Spatial Implications of the Neo-Rawlsian Exercise}

If we were to accept that relationally-based persons (desiring 'meaningful relationships'), behind a veil of ignorance would desire the aforementioned attributes, there are very real spatial implications. Where the first feature (real relationships) would technically only require bonding networks for its realization in society, the desire for a full range of social expressions by which to build and shape one's identity would require what has been referred to as 'bridging capital'-or associations that 'bridge' across diverse groups of people creating heterogeneous social networks. To realize this desire in the basic structure, institutions should lubricate the grounds for contact among differing individuals on levels such as race, class, or culture. As mentioned, an appropriate arrangement for enhanced contact would likely involve housing. Neighborhoods offer a natural platform for social intercourse through increased contact, shared amenities and goods, and collective responsibility. Such diversity offers a practical means by which to widen my self-identity and understanding, in addition to establishing norms of trust and reciprocity along more diverse lines. Conversely, a segregated neighborhood may serve to limit my ability to aspire to a healthy balance of self-understanding and personality as I would be limited to social development within a limited, and potentially rigid, environment. There are social consequences for such an arrangement, as Stolle et al. (2008) write: '...social interactions among homogeneous individuals may actually make it much harder-or even impossible-for individuals to transfer 
their in-group trust to the outside world' ([40], p. 60). Not only would being born in a homogeneous community limit my own self-identity, understanding, and potential-but it would make it very difficult to socially navigate an increasingly diverse world.

Thus, the second implication of the neo-Rawlsian exercise would likely support residential integration. The support of integrated neighborhoods on racial terms will have natural implications for socio-economic and cultural integration as well. Thickly-constituted selves would desire the opportunity to identify with different races so as to have a fuller understanding of themselves and human beings in general. As Putnam writes: 'social distance depends...on social identity: our sense of who we are. Identity itself is socially constructed and can be socially de-constructed and reconstructed' ([41], p. 159). Navigating through identities, or what Putnam refers to as the 'intentional transformation of identities' requires a 'dynamic and evolving society' ([41], p. 159). Thus, exposure to different races in an integrated neighborhood setting provides a full palette of social expressions by which to identify myself with, which allows me to re-construct my own identity. Putnam offers a practical advantage to this social flexibility: '...adapting over time, dynamically, to immigration and diversity requires the reconstruction of social identities, not merely of the immigrants themselves (though assimilation is important), but also of the newly more diverse society as a whole (including the native born)' ([41], pp. 159$160)$. In a society of ever-changing ethnic and racial composition-flexibility is a necessary attribute since 'the most certain prediction that we can make about almost any modern society is that it will be more diverse a generation from now than it is today' ([41], p. 137).

Third, and finally, thickly-constituted persons behind a veil of ignorance would desire to maximize security and minimize enmity. The connection between space and conflict is easily visible and the examples are legion. Persons in the original position may offer the following question: 'if I was unaware of my race, religion, ethnicity, culture, gender, etc.-would I want to enter a world where I could be born into conflict with a distinct person or group?' For example, an African American born into southern US territory in the mid-1800s is born into conflict with white landowners. Equally so, being born into gang territory, political territory, or border territory among rival ethnicities or cultures is to inherit a conflict with a distinct 'other' upon entering the world. This is not to suggest that segregation always causes tension, but to point out that spatial tension is evident in residentially segregated areas as well.

As these examples make clear, the 'other' is often defined in spatial terms. However, this does not presume that space is the problem-only a mechanism of identification. Indeed, it would be wrong to assume that enmity is absent in integrated spaces.
Moreover, tension within an integrated space may actually lead to spatial segmentation, suggesting a mutual causality between tension and segregation (segregation can produce tension, but tensionsometimes originating from 'integrated' spaces-can produce segregation). Related to this, consider the remarks of Stolle et al. (2008):

A growing body of evidence suggests that localities, neighborhoods, regions or states and even countries with more ethnic, racial and socio-economic diversity experience substantially more problems with the creation of various kinds of social capital, cooperation, trust and support necessary for collective action critical to social welfare programs ([40], p. 57).

There are two points to reflect upon here. First, if there is enmity within space (i.e., integrated space), then it does not necessarily follow that segregation is the solution. This may only make tensions worse by establishing a defined 'we' in conflict with a defined 'them' and exacerbating out-group hostility. Second, as mentioned, we should not presume that space is the problem. Rather, it may be a symptom of the problem, which is better understood as the absence of healthy contact thus creating more fear and a lack of rationality. We can remark, however, that space and spatial integration is a part of the solution-although not the direct solution. If thickly-constituted agents in the original position desire the maximization of security and the minimization of enmity-then we may say that they desire an integrated society constituted by shared norms and collective mindfulness and responsibility. The achievement of integration of this sort requires, as a baseline, shared space and close proximity. This is a necessary overture toward harmonious community relationships so as to introduce new social dynamics necessary for healthy integration to occur. We may conclude, therefore, that this feature also supports the cultivation of bridging networks and would equally support residential integration as a means of achieving this strand of social capital.

\section{Conclusions}

To solely explore the economic implications of segregation/integration is to risk missing a larger moral and ethical dimension. As mentioned, this is not to suggest that an economic dimension is devoid of moral considerations. Rather, this paper has argued for a more capacious moral argument as it relates to our social arrangements (normative argument). These elements include (a) considerations in fairness and social equity as well as (b) considerations as to the essence of integration.

Further, this paper has endeavored to give philosophical support to the normative argument by utilizing a Rawlsian framework. This framework, it has been argued, is sufficient to support the first feature of the normative argument (social equity), but insuffi- 
cient to support its second feature (essentialist argument for integration). To maintain the integrity of the first argument while giving additional support for the second, a neo-Rawlsian framework was suggested, where agents behind a veil of ignorance were 'thickly' constituted with a desire for meaningful relationships (in addition to their desire for other primary social goods).

Some will likely question the nature of this exercise, as Rawls' original 'thinly' constituted agent behind a veil of ignorance would only desire primary social goods such as liberty, wealth, and opportunity that would allow them to choose their social networks. Moreover, it is likely that some would argue this exercise infringes upon, or de-emphasizes, choice as an important feature of a liberal democracy. For example, Imbroscio (2004) presents a case for the liberty of 'choice' in the context of place with the underlying notion that choosing where one wants to live is a fundamental freedom and remains a positive human right for all human beings [42]. Specifically, Imbroscio supports what has been referred to as 'community integrity' ([43], p. 595). Integrity, in contrast to the goal of integration, upholds the right to travel or stay put as a tenet of the US constitution and as the 'fabric of American life' ([44], p. 578). This notion, which would likely garner support from the original Rawlsian exercise, promotes spatial equality above any attempts to engineer integration: 'real freedom of residential choice should be conceived of as dyadic, expanding both the exit/entry opportunities for the urban poor as well as possibilities to stay put; it should, consequently, be constituted by policy efforts to facilitate mobility as well as efforts to make inner cities more livable' ([45], p. 123). In other words, instead of supporting integrated environments, respecting individual rights would require the primacy of spatial equality and choice for all social agents.

While much can be said in relation to choice, a few cursory responses are necessary. First, as this paper has pointed out, engineered mixing (spatial integration) is distinct from organic mixing (social integration). In other words, 'mix' may be good, but it doesn't follow that 'mixing' is good. Even if one accepts the terms of the neo-Rawlsian exercise, this still requires thoughtful consideration as to how integrated arrangements are arrived upon. Steps can be taken to fertilize the grounds for spatial mixing patterns, but this is altogether different from a forced arrangement. Thus, choice should always be a feature of healthy social engagement-but this does not prohibit us from reflecting upon our choices and how they are arrived upon.

Second, and related, the primacy of choice is the primacy of preference. However, where do those preferences originate from? Economists are primarily concerned with the consequences of our preferences, but not necessarily their origin (preference formation). Our preferences, desires, and choices are, however, conceived and developed within a certain environment. Living within a segregated arrangement is likely to breed preferences that reinforce segregation (referred to earlier as path dependency).

Finally, the expression of one's preference still does not make that particular preference immune from moral evaluation. For example, the preference for participation in a hate group (e.g., the $K K K$ ) is hardly a morally superior arrangement-even though it could be rightfully described as an expression of 'choice'.

These points support the usefulness of the neoRawlsian exercise, as thickly constituted agents reflect the value and importance of relationships for human beings, but still allow for deliberation behind a veil of ignorance. This does not de-emphasize choice or human freedom in society (attributes supported by the Rawlsian framework). However, it does recognize that-in an abstract 'original position'-bonding and bridging networks would be an attractive attribute of the social landscape we might later inhabit, and this has implications for how we might consider integration.

To summarize the two aforementioned features and their spatial implications-space is a necessary component for real relationships, a more comprehensive setting for identity formation, and for the maximization of security and the minimization of enmity. Moreover, among other things, the spatial implications of the aforementioned features allow for a more concise statement that thickly-constituted agents in the original positions would likely agree upon: they would desire a society that is socially integrated. This term, introduced earlier, makes the important distinction that proximity does not equal acceptance or that shared space does not equal inclusion. In other words, spatial integration does not equate with social integration. Thus, where spatial integration may refer to close proximity and shared space-social integration refers to close proximity, shared space, and inclusion, or the idea of social assimilation where trust, cooperation, and collective responsibility define the norms of such membership.

Spatial segregation may be a problem or even the problem-but it does not follow that integration, in general, is the solution. The answer lies in the kind of integration we want (social; not simply spatial). Social integration is much more morally thick and ethically charged understanding of integration. Could it be that our failure to discuss integration in these terms (ethical terms) has reinforced the problem of segregation and our attempts to integrate? Could it be that communicating the problem of segregation solely on the terms of utility and economic efficacy has stripped the idea of social integration of its ethical flavor and, in doing so, has redefined the norms of integration leaving us to ask the wrong questions? If the impetus to integrate originated from the premise that ' $m i x$ ' is good (i.e., ethically right and morally appropriate), might this change how we think about, conduct, and measure mixing overtures? 
This article has argued that a fundamental shift in our social ethos is necessary to lubricate a pathway where social, not simply spatial, integration can occur. This begins, it is suggested, with framing the argument in ethical, in addition to economic, terms. Integration as an ethically right and socially just feature offers moral rationale as to why residential mixing would be an appropriate social desire worthy of pursuit. However, when the argument is communicated solely in the language of the economic paradigm, we change the norms of the argument and important ethical considerations and features are lost in the translation. Efficiency is an important consideration, but not at the expense of larger moral considerations.

\section{References and Notes}

1. Goetz E. Housing Dispersal Programs. Journal of Planning Literature. 2003;18(3):3-16.

2. Logan J. Ethnic Diversity Grows, Neighborhood Integration Lags Behind. Albany, NY, USA: Lewis Mumford Center; 2001. pp. 1-32.

3. Massy DS, Denton NA. American Apartheid: Segregation and the Making of the Underclass. Cambridge, MA, USA: Harvard UP; 1993.

4. Flippen $C$. Unequal Returns to Housing Investments? A Study of Real Housing Appreciation among Black, White, and Hispanic Households. Social Forces. 2004;82(4):1523-1551.

5. Vartanian TP, Buck PW, Gleason P. Intergenerational Neighborhood-Type Mobility: Examining Differences between Blacks and Whites. Housing Studies. 2007;22(5):833-856.

6. Collins WJ, Margo RA. Residential Segregation and Socioeconomic Outcomes: When Did Ghettos Go Bad? Economics Letters. 2000;69(2):239-243.

7. Williams DR, Collins C. Racial Residential Segregation: A Fundamental Cause of Racial Disparities in Health. Public Health Reports. 2001;116(5):404-416.

8. Cutler DM, Glaeser EL. Are Ghettos Good or Bad? The Quarterly Journal of Economics. 1997;112 (3):827-872.

9. Dreier P, Moberg D. Moving From the 'Hood: The Mixed Success of Integrating Suburbia. The American Prospect. 2001. Available from http://www. prospect.org/cs/articles?article=moving_from_the_ho od (accessed on 1 June 2010).

10. Schwartz A, Tajbakhsh K. Mixed-Income Housing: Unanswered Questions. Cityscape: A Journal of Policy Development and Research. 1997;3(2):71-92.

11. Hartman CW, Squires GD. Integration Exhaustion, Race Fatigue, and the American Dream. In: Hartman $\mathrm{CW}$, Squires GD, editors. The Integration Debate: Competing Futures for American Cities. New York, NY, USA: Routledge; 2010.

12. Anderson $\mathrm{E}$. The Imperative of Integration. Princeton, NJ, USA: Princeton UP; 2010.

13. Wolff J, De-Shalit A. Disadvantage. Oxford, UK:
Therefore, given the relational nature of humans and the communities they inhabit in a society, a more appropriate approach to the larger residential integration discussion would be to invite ethical deliberation into the discussion. An ethical dimension is important -we may even say necessary - to achieve the social integration (where mix is both a means to an end and an end in itself) that engineered or 'imposed' efforts can only aspire to. Citizens who find themselves morally impelled by the ethical argument to mix-in addition to conditions that fertilize the grounds for integration to occur-may best cultivate the necessary means that allow for an organic progression of residential, and more importantly, social integration.

Oxford UP; 2010.

14. Sen A. On Economic Inequality. Oxford, UK: Clarendon; 1997.

15. Velasquez MG. Business Ethics: Concepts and Cases. Englewood Cliffs, NJ, USA: Prentice Hall; 1982.

16. To assert that utilitarianism is concerned with consequences and morality and justice is not would be inaccurate, as achieving justice, for example, has a particular end in mind-though it may not necessarily be a material end (e.g., achieving a sense of belonging).

17. Karst KL. Paths to Belonging: The Constitution and Cultural Identity. North Carolina Law Review. 1985;64(1):302-379.

18. A notable exception would be Elizabeth Anderson's 2010 work 'The Imperative of Integration' [12]. Here, Anderson suggests that 'integration of racial, ethnic, and other groups that mark significant lines of social inequality is a vital ideal for the democratic society, necessary for its basic institutions to function successfully' ([12], p. x). Anderson concerns herself with socially integrated living arrangements, but the normative thrust of her argument relates to inequality between black and white households. See [12].

19. Cheshire P. Policies for Mixed Communities: Faith-Based Displacement Activity? International Regional Science Review. 2009;32(3):1-32. Available from: http://eprints.Ise.ac.uk/30783/1/Policies_for_mi xed_communities_(LSERO_version).pdf (accessed on 15 August 2013).

20. Mandle J. Rawls' A Theory of Justice: An Introduction. Cambridge, UK: Cambridge UP; 2009.

21. Rawls J. A Theory of Justice. New Delhi, India: Universal Law; 1971.

22. Beaumont J. Faith Action on Urban Social Issues. Urban Studies. 2008;45(10):2019-2034.

23. Velasquez MG, Rostankowski C. Ethics, Theory and Practice. Englewood Cliffs, NJ, USA: Prentice-Hall; 1985.

24. Curtis M. The Great Political Theories. Volume 2. New York, NY, USA: Avon; 1981.

25. Philosopher Jonathan Wolff offers a contemporary understanding of the original position and the accompanying veil of ignorance: 'suppose you have just 
woken up in a hospital bed. First you realize that you are suffering from an extensive memory loss. Looking down you see that you are swaddled from head to toe in bandages. You don't remember your name, sex, or race, nor can you discover these by self-inspection (the tag on your bandaged wrist only has a number). Facts about your family, occupation, class, strengths, skills, and so on are all lost to you. You do recall some general theories you once learnt in economics and sociology classes, but you cannot remember anything from your history lessons. In fact, you could not even say what century it was. Then into the ward walks a man in a white coat. "Good morning", he says, "I am Professor John Rawls. Tomorrow your memory will return, your bandages will be removed, and you will be free to leave. So we don't have much time. What we need you to do is to tell us how you would like society to be designed, bearing in mind that, from tomorrow, you will be living in the society you have chosen. We want you to design society purely in your own interests. Although you do not know what your actual interests are, I can tell you that you want as many primary goods as possible-liberties, opportunities, wealth, and income-and you should not consider the fortunes of anyone else. I will come back this evening to see what you have decided." Under these conditions, what would it be rational to choose?' (p. 159) See: Wolff J. An Introduction to Political Philosophy. Oxford, UK: Oxford UP; 2006.

26. Specifically, Cheshire writes, "Indeed, it can be argued specialisation is the central contribution of cities to progress and welfare" ([19], p. 5).

27. While the literature is extensive regarding the associated disadvantages of segregated, low-income neighborhoods - there is a distinction between a high correlation among segregated, deprived neighborhoods and constrained life chances and the assertion that neighborhoods cause such constraints. For example, as it relates to poverty, we might ask: is an impoverished neighborhood a reflection of poverty, or does it actually cause poverty?

28. Rawls offers two theories of justice he believes rational and mutually disinterested agents in the original position would agree upon. The first principle is that each person is to have an equal right to the most extensive total system of basic liberties compatible with a similar system of liberty for all. The second principle is that social and economic inequalities are to be arranged so that they are both (a) to the greatest benefit of the least advantaged, consistent with the just savings principle, and (b) attached to offices and positions open to all under conditions of fair equality of opportunity. See: ([21], p. 302).

29. Wolff J. Why Read Marx Today? New York, NY, USA: Oxford UP; 2002.

30. Kymlicka W. Liberal Individualism and Liberal
Neutrality. Ethics. 1989;99(4):883-905.

31. Fergusson D. Community. Liberalism and Christian Ethics. Cambridge, UK: Cambridge UP; 1998. This quote should not suggest that a shift from 'thin' to 'thick' is a clear shift from individual preferences to relations in a community. Rather, it is to recognize that agents behind a veil of ignorance-in addition to desiring the existing primary social goods (liberty, wealth, opportunity)-are relationally constituted agents and, as such, would utilize their primary goods and pursue their ends in a way that would reflect this. In other words, our individual and communal attributes are not zero-sum. Rather, as Etzioni (1996) has suggested, they exist within a symbiotic relationship where the two forces enrich one another 'rather than merely work well together' ([32], p. 34).

32. Amitai Etzioni. The New Golden Rule: Community and Morality in a Democratic Society. New York, NY, USA: Basic; 1996.

33. Putnam RD. Bowling Alone: The Collapse and Revival of American Community. New York, NY, USA: Simon \& Schuster; 2000.

34. T. Schuller, Baron S, Field J. Social Capital: A Review and Critique. In: Baron S, Field J, Schuller T, editors. Social Capital. Oxford, UK: Oxford University Press; 2000.

35. Walzer M. Spheres of Justice: A Defense of Pluralism and Equality. New York, NY, USA: Basic; 1983.

36. Putnam RD, Feldstein LM, Cohen D. Better Together: Restoring the American Community. New York, NY, USA: Simon \& Schuster; 2003.

37. De Souza Briggs X. 'Some of My Best Friends Are...': Interracial Friendships, Class, and Segregation in America. City and Community. 2007;6(4):263-290.

38. Emerson MO, Yancey G, Chai KJ. Does Race Matter in Residential Segregation? Exploring the Preferences of White Americans. American Sociological Review. 2001;66(6):922-935.

39. Amy Gutmann in [33].

40. Stolle D, Soroka S, Johnston R. When Does Diversity Erode Trust? Neighborhood Diversity, Interpersonal Trust and the Mediating Effect of Social Interactions. Political Studies. 2008;56(1):57-75.

41. Putnam RD. E Pluribus Unum: Diversity and Community in the Twenty-first Century The 2006 Johan Skytte Prize Lecture. Scandinavian Political Studies. 2007;30(2):137-174.

42. Imbroscio DL. Can We Grant a Right to Place? Politics and Society. 2004;32(4):575-609.

43. Gordon Clark in [42].

44. Paul Dimond in [42].

45. This, Imbroscio contends, achieves one of the original policy goals in housing from the 1949 housing act: 'to provide housing for Americans in a suitable living environment' ([42], p. 123). 